\title{
Evaluation of dimensional accuracy for different complete edentulous impressions immersed in different disinfectant solutions
}

\author{
Hussein Abdelfattah Ismail ${ }^{1}$, Hamada Z. Mahross ${ }^{2}$, Suaad Shikho ${ }^{1}$
}

Correspondence: Dr. Hussein Abdelfattah Ismail Email: hussien_eldwash@yahoo.com
'Department of Removable Prosthodontics, Al-Farabi Collages, KSA,

${ }^{2}$ Department of Removable Prosthodontics, Alazhar Univeristy, Cairo, Egypt

\begin{abstract}
Objective: The aim of this study was to evaluate the effects of two different disinfectant solutions' immersion on the dimensional accuracy of different complete edentulous impressions. Materials and Methods: A specific custom-made metallic cast template was constructed and used for making both 120 alginate and zinc oxide eugenol (ZOE) paste impressions (60 for each). Disinfectants with $1 \%$ sodium hypochlorite and $2 \%$ glutaraldehyde were used for 10 and 60 min immersion of both impressions. After immersion time, the impressions were used for constructing 120 completely edentulous master stone models and divided into different groups according to the study. An electronic caliper was used for dimensional accuracy measurements of the casts. The data were collected and statistically analyzed according to the independent paired sample $t$-test at statistically significant level $P<005$. One-way ANOVA test was used to compare between significant different groups. Results: There is no statistically significant difference in dimensional accuracy of alginate and ZOE paste impressions as disinfection with $1 \%$ sodium hypochlorite and $2 \%$ glutaraldehyde for $10 \mathrm{~min}$ and ZOE paste impressions for $60 \mathrm{~min}$, where there is statistically significant difference in alginate impressions dimensional accuracy as disinfection with $1 \%$ sodium hypochlorite and $2 \%$ glutaraldehyde for 60 min. Conclusions: Possibility of ZOE impressions paste disinfected with 1\% sodium hypochlorite and $2 \%$ glutaraldehyde for 10 or 60 min, not affecting on dimensional stability, while alginate impressions, only 10 min immersion in disinfectant not affecting the dimensional stability.
\end{abstract}

Key words: Dimensional accuracy, disinfection, final impressions, glutaraldehyde, sodium hypochlorite

\section{INTRODUCTION}

Dental impressions are often contaminated with microorganisms even washing them under tap water does not always guarantee that all organisms have been removed. The Center for Disease Control and the American Dental Association (ADA) have recommended disinfection of impression immediately after removal from the mouth. This prevents cross-contamination of infectious diseases such as hepatitis B, tuberculosis, herpes,

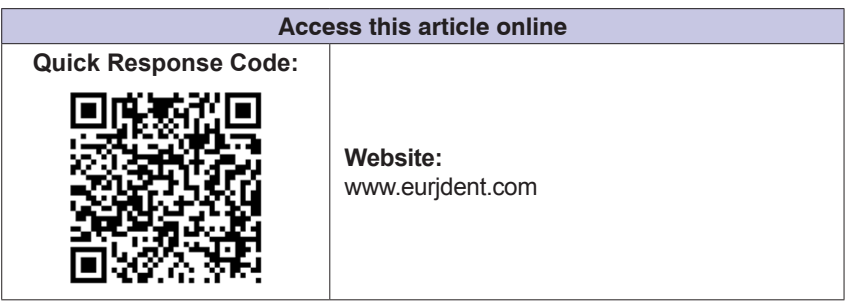

and acquired immune deficiency syndrome from the patient to the dentist and laboratory technician. ${ }^{[1-9]}$

The ADA has been registered various chemical disinfectants such as glutaraldehyde, chlorine compounds, iodophors, and phenols for immersion

This is an open access article distributed under the terms of the Creative Commons Attribution-NonCommercial-ShareAlike 3.0 License, which allows others to remix, tweak, and build upon the work non-commercially, as long as the author is credited and the new creations are licensed under the identical terms.

For reprints contact: reprints@medknow.com

How to cite this article: Ismail HA, Mahross HZ, Shikho S. Evaluation of dimensional accuracy for different complete edentulous impressions immersed in different disinfectant solutions. Eur J Dent 2017;11:242-9.

DOI: $10.4103 /$ ejd.ejd_268_16 
disinfection of impression materials..$^{[8,10,11]}$ Therefore, chemical disinfectants such as $2 \%$ glutaraldehyde and $0.5 \%$ sodium hypochlorite have a broad-spectrum antimicrobial activity such as bactericidal, tuberculocidal, fungicidal, virucidal, and sporicidal. However, 0.05\% iodophor and $5.25 \%$ phenol have a broad-spectrum antimicrobial activity except for sporicidal. ${ }^{[12]}$ Sodium hypochlorite has been shown to be a fast-acting broad-spectrum disinfectant for irreversible hydrocolloid impressions and zinc oxide eugenol (ZOE) paste. ${ }^{[1]}$

It is important that disinfectant solutions should be not only effective as antimicrobial agents but also should not degrade the physical properties of the impression material to produce dies as clinically accurate and smooth as the master cast. However, disinfectants are chemical solutions can produce a chemical or physical reaction with impression materials so that the impressions dimensional may be affected in immersion with subsequent effects on dentures' stabilization in addition to other factors affecting the stability of prosthetic dentures as the correct diagnosis and appropriate treatment plan. ${ }^{[3]}$ It has been proposed that the disinfectant treatments are found to alter the surface chemistry of an impression material that may change the hydrophilicity of the impression material. ${ }^{[8]}$

Studies have shown that sodium hypochlorite is an effective disinfectant requiring $<30$ min of immersion. Another advantage of using sodium hypochlorite solution is its low cost. However, because of its poor stability over a period of time, the solution must be made fresh daily to ensure its efficacy ${ }^{[13,14]}$ Much work has been undertaken, and results have been reported regarding the surface changes and dimensional stability of the impression material that is subjected to different immersion disinfectants. ${ }^{[11,15-19]}$

However, the effect of various disinfectants in dimensional accuracy of impression materials to produce accurate master cast is still questionable. Therefore, this in vitro study was planned to evaluate the effect of commercially available and most commonly used disinfectants ( $1 \%$ sodium hypochlorite and $2 \%$ glutaraldehyde) on impression materials (irreversible hydrocolloid and ZOE paste impressions) that can be poured into stone casts, and main metallic cast template was conducted. The study will be also clarified that comparing the dimensional accuracy on different materials at different time (10 and $60 \mathrm{~min}$ ) and the measurements between the stone casts produced from both different impressions and the main metallic cast template.
The null hypothesis tested was that the different types of disinfectants used would produce similar effects on the dimensional accuracy of the various impression materials and the resultant casts.

\section{MATERIALS AND METHODS}

A 120 maxillary complete edentulous stone casts (Elite, Rock Company, USA) were included in the study; this type of stone has been used because it has little setting expansion $(0.04 \%)$ after $2 \mathrm{~h}$ of pouring. These casts were constructed from pouring a 120 maxillary alginate (Tropicalgin, Zhermack, Italy) and ZOE paste impressions (SS White Impression Paste, White, England) made from a custom-made metallic maxillary complete edentulous template.

The metallic cast template has a positioning four prisms with $2 \mathrm{~mm}$ in height above the top of edentulous ridge and perfectly parallel to each other. The localization of the prisms was distributed and demarcated as the following [Figure 1]:

- Prism in the right canine called Prism A

- Prism in the left canine called Prism B

- Prism in the left second molar called Prism C

- Prism in the left second molar called Prism D.

An electronic caliper (IOS, ROH NORM 2002/95/ EC-USA) with $0.02 \%$ accuracy was used for measurement; four measurements were recorded as the following:

- A-B: Distance from the external wall of Prism A to the external parallel wall of Prism B

- C-D: Distance from the external wall of Prism C to the external parallel wall of Prism D

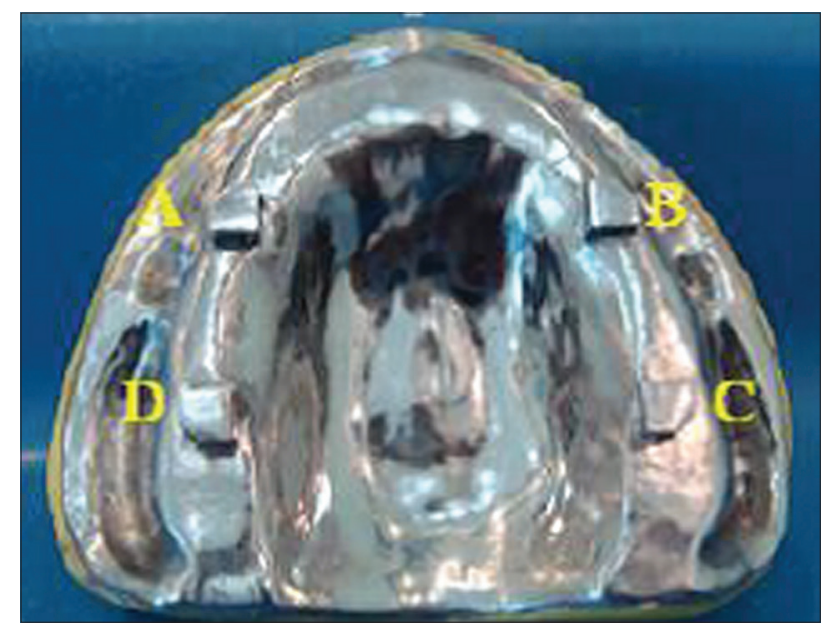

Figure 1: Localization and demarcation of prisms A-D on the metallic template 
- A-C: Distance diameter between external beveled parallel surfaces

- D-B: Distance diameter between the external beveled parallel surfaces.

For impressions specimens' preparation, a 120 light-cured acrylic resin custom made were constructed with 3 tissue stops at ridge crest (2 at molar area and 1 at incisor area). The spacer with its stops was constructed by adapting a double layer (for alginate) and one layer (for ZOE) of modeling wax thickness to maintain the even thickness of impression material and stabilize the tray during impression procedures. The trays used for making 60 alginate impressions were perforated whereas the trays used for making $60 \mathrm{ZOE}$ impressions were none perforated.

The trays loaded (after mixing according to manufacturer instructions) with either impression materials were aligned perpendicular over the metallic cast during impression making. The trays were used for making $60 \mathrm{ZOE}$ paste impressions of the metallic cast template after isolation by painting thin separating media of silica to prevent adhesion of impression to the template. The trays were border molded with green stick compound (Green impression compound, Kerr, Switzerland) and loaded with ZOE paste. All procedures were performed with the same instruments, mixed time, proportions, and setting time. After setting removed and washed under running water for $10 \mathrm{~s}$.

After setting removed and washed under running water for $10 \mathrm{~s}$. A 30 alginate and a 30 ZOE impressions immersed in $1 \%$ sodium hypochlorite for $10 \mathrm{~min}$. A 30 alginate and a $30 \mathrm{ZOE}$ impressions immersed in $2 \%$ glutaraldehyde for $10 \mathrm{~min}$.

- Group 1:A 15 alginate impressions disinfected with $1 \%$ sodium hypochlorite were poured immediately after removal from disinfectant, then separated from impression after $1 \mathrm{~h}$ of setting

- Group 2: A 15 alginate impressions disinfected with $2 \%$ glutaraldehyde were poured immediately after removal from disinfectant then separated from impression after $1 \mathrm{~h}$ of setting

- Group 3: A 15 alginate impressions disinfected with $1 \%$ sodium hypochlorite (15) and $2 \%$ glutaraldehyde (15) for 10 min were stored in a plastic tightly closed bottle with wetted napkin (as in daily manner) at room temperature for $1 \mathrm{~h}$, after that poured with stone

- Group 4: A 15 alginate impressions disinfected with $1 \%$ sodium hypochlorite (15) and $2 \%$ glutaraldehyde (15) for $10 \mathrm{~min}$ were stored in a plastic tightly closed bottle with wetted napkin (as in daily manner) at room temperature for $3 \mathrm{~h}$, after that poured with stone

- Group 5: A 15 ZOE paste impressions disinfected with $1 \%$ sodium hypochlorite were poured immediately after removal from disinfectant with stone then separated from impression after $1 \mathrm{~h}$ of setting

- Group 6: A 15 ZOE paste impressions disinfected with $2 \%$ glutaraldehyde were poured immediately after removal from disinfectant with stone then separated from impression after $1 \mathrm{~h}$ of setting

- Group 7: A 30 ZOE paste impressions disinfected with $1 \%$ sodium hypochlorite (15) and $2 \%$ glutaraldehyde (15) were stored in a plastic tightly closed bottle in dry environment at room temperature for $3 \mathrm{~h}$, after that poured with stone.

An electronic caliper with $0.02 \%$ accuracy was used for measurement of all the casts as performed in metallic cast template. Four measurements were recorded for each cast and compared with the records measured for metallic cast template [Figure 2].

The data were collected and statistically analyzed at statistically significant level $P<005$ according to:

- One-sample $t$-test was used for compared measurements between the stone casts produced from both different impressions and the main metallic cast template

- The independent samples $t$-test was used for compare measurements between stone casts produced from two different impression materials

- One-way ANOVA test was used for compare measurements between stone casts produced from the same impression materials.

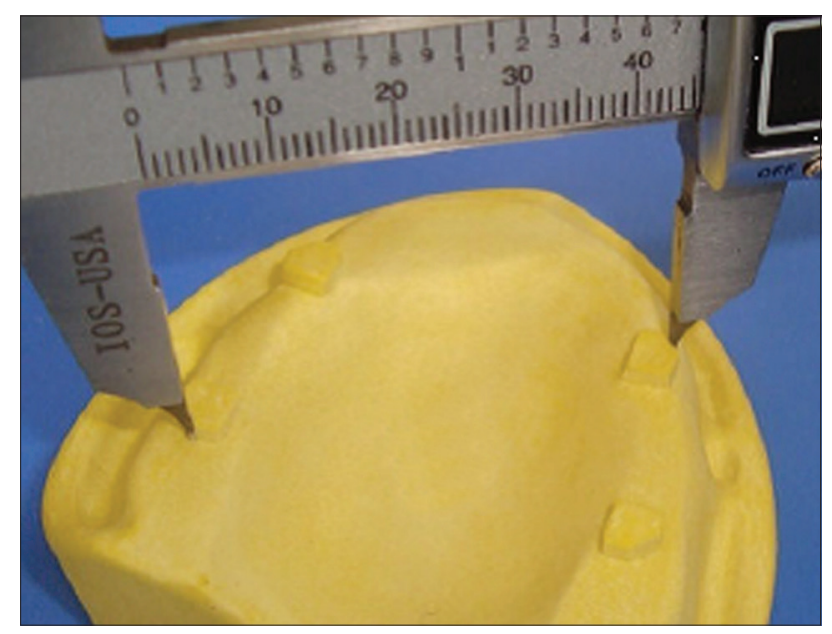

Figure 2: Electronic caliper used for measurement the distance between prisms on the stone cast 


\section{RESULTS}

To evaluate the error of measurement method, 10 casts of stone were selected and measured twice, and the $t$-paired test was showed that there is no significant difference between the two measurements at the level of confidence of $95 \%$ so that method error is obsolete.

Table 1 shows that the value measurements between prisms (A-B, C-D, A-C, D-B) on the metallic master model were used in the study.

Table 2 shows that average, standard deviation, standard error, maximum, minimum, sample size, and groups for measurements (A-B, C-D, A-C, D-B) for alginate and ZOE paste impressions immersed in $1 \%$ sodium hypochlorite and $2 \%$ glutaraldehyde solutions for $10 \mathrm{~min}$ then immediately poured to gypsum stone.

Table 3 shows that one-sample $t$-test was used to analyze comparison results when $(P<0,05)$ there is no statistically significant difference between measurements were taken from immediately poured casts after immersed in $1 \%$ sodium hypochlorite and $2 \%$ glutaraldehyde solutions for $10 \mathrm{~min}$ with measurements from the metallic master model.

Table 1: Average values of the metallic cast template
measurements
\begin{tabular}{lcccc}
\hline Measurement & A-B & C-D & A-C & D-B \\
\hline Value & 39.69 & 45.59 & 46.47 & 45.77 \\
\hline
\end{tabular}

Table 4 shows that average, standard deviation, standard error, maximum, minimum, sample size, and groups for measurements (A-B, C-D, A-C, D-B) for alginate and $\mathrm{ZOE}$ paste impressions immersed in $1 \%$ sodium hypochlorite and $2 \%$ glutaraldehyde solutions for $60 \mathrm{~min}$ then immediately poured to gypsum stone.

One-sample $t$-test was used to analyze comparison results for measurements $(\mathrm{A}-\mathrm{B}, \mathrm{C}-\mathrm{D}, \mathrm{A}-\mathrm{C}, \mathrm{D}-\mathrm{B})$ for alginate and ZOE paste impressions, these immersed in $1 \%$ sodium hypochlorite and $2 \%$ glutaraldehyde solutions for $60 \mathrm{~min}$ then immediately poured in gypsum stone [Table 5].

\section{DISCUSSION}

The results of the present study were indicated that the null hypothesis can be partly accepted because immersion disinfection with $1 \%$ sodium hypochlorite and $2 \%$ glutaraldehyde solution concentrations for $10 \mathrm{~min}$ did not alter the dimensions of the alginate and ZOE paste impressions and the subsequent pouring casts which affect later on the stability of prosthetic dentures. Therefore, with accordance to the statistical analysis of the study, it was founded that there was no statistically significant difference between the fourth of measurements (A-B, C-D, A-C, and D-B) for master metallic model with immediately poured casts of alginate and ZOE paste impressions after immersing in 1\% sodium hypochlorite and $2 \%$ glutaraldehyde solution concentrations for $10 \mathrm{~min}$. These results come in coincidence with the results of Bustos et al. who concluded that, when $1 \%$ sodium

\begin{tabular}{|c|c|c|c|c|c|c|c|}
\hline Measurement & Group & Sample size & Average & SD & SE & Maximum & Minimum \\
\hline A-B & 1 & 15 & 39.70 & 0.0334 & 0.0086 & 39.75 & 39.65 \\
\hline C-D & 1 & 15 & 45.600 & 0.0220 & 0.0056 & 45.65 & 45.57 \\
\hline$A-C$ & 1 & 15 & 46.480 & 0.0281 & 0.0072 & 46.52 & 46.44 \\
\hline D-B & 1 & 15 & 45.781 & 0.0238 & 0.0061 & 45.83 & 45.74 \\
\hline$A-B$ & 2 & 15 & 39.70 & 0.035 & 0.009 & 39.75 & 39.65 \\
\hline C-D & 2 & 15 & 45.60 & 0.028 & 0.007 & 45.65 & 45.55 \\
\hline$A-C$ & 2 & 15 & 46.47 & 0.015 & 0.003 & 46.50 & 46.45 \\
\hline D-B & 2 & 15 & 45.77 & 0.018 & 0.004 & 45.81 & 45.75 \\
\hline$A-B$ & 5 & 15 & 39.68 & 0.039 & 0.0102 & 39.75 & 39.62 \\
\hline C-D & 5 & 15 & 45.59 & 0.033 & 0.008 & 45.66 & 45.55 \\
\hline$A-C$ & 5 & 15 & 46.49 & 0.050 & 0.013 & 46.57 & 46.42 \\
\hline D-B & 5 & 15 & 45.77 & 0.042 & 0.010 & 45.82 & 45.70 \\
\hline$A-B$ & 6 & 15 & 39.68 & 0.044 & 0.011 & 39.77 & 39.62 \\
\hline C-D & 6 & 15 & 45.60 & 0.045 & 0.011 & 45.68 & 45.53 \\
\hline$A-C$ & 6 & 15 & 46.48 & 0.040 & 0.010 & 46.54 & 45.42 \\
\hline D-B & 6 & 15 & 45.76 & 0.038 & 0.009 & 45.82 & 45.70 \\
\hline
\end{tabular}


Ismail, et al.: Impression disinfectant solutions

\begin{tabular}{|c|c|c|c|c|c|}
\hline Measurement & The difference between the mean (1) & SE & Degree of freedom & Value $t$ calculated & Value $P<0.05$ \\
\hline$\overline{A-B}$ & 0.017 & 0.0086 & 14 & 2005 & 0.065 \\
\hline C-D & 0.010 & 0.0056 & 14 & 1757 & 0.101 \\
\hline$A-C$ & 0.010 & 0.0072 & 14 & 1468 & 0.164 \\
\hline D-B & 0.011 & 0.0061 & 14 & 1839 & 0.087 \\
\hline Measurement & The difference between the mean (2) & SE & Degree of freedom & Value $t$ calculated & Value $P<0.05$ \\
\hline A-B & 0.014 & 0.009 & 14 & 1549 & 0.144 \\
\hline C-D & 0.010 & 0.007 & 14 & 1442 & 0.171 \\
\hline$A-C$ & 0.006 & 0.003 & 14 & 1.67 & 0.116 \\
\hline D-B & 0.009 & 0.004 & 14 & 1.97 & 0.068 \\
\hline Measurement & The difference between the mean (5) & SE & Degree of freedom & Value $t$ calculated & Value $P<0.05$ \\
\hline$\overline{A-B}$ & 0.004 & 0.010 & 14 & 0.456 & 0.655 \\
\hline C-D & 0.008 & 0.008 & 14 & 0.933 & 0.367 \\
\hline$A-C$ & 0.023 & 0.013 & 14 & 1794 & 0.094 \\
\hline D-B & 0.013 & 0.010 & 14 & 1.22 & 0.239 \\
\hline Measurement & The difference between the mean (6) & SE & Degree of freedom & $\begin{array}{c}\text { Value } t \\
\text { Calculated }\end{array}$ & Value $P<0.05$ \\
\hline A-B & 0.004 & 0.010 & 14 & 0.456 & 0.655 \\
\hline C-D & 0.008 & 0.008 & 14 & 0.933 & 0.367 \\
\hline$A-C$ & 0.023 & 0.013 & 14 & 1794 & 0.094 \\
\hline D-B & 0.013 & 0.010 & 14 & 1.22 & 0.239 \\
\hline
\end{tabular}

\begin{tabular}{|c|c|c|c|c|c|c|c|}
\hline Measurement & Group & Sample size & Average & SD & SE & Maximum & Minimum \\
\hline$\overline{A-B}$ & 3 & 15 & 39.724 & 0.0534 & 0.0137 & 39.81 & 39.65 \\
\hline C-D & 3 & 15 & 45.668 & 0.0796 & 0.0205 & 45.80 & 45.55 \\
\hline$A-C$ & 3 & 15 & 46.592 & 0.1360 & 0.0351 & 46.87 & 46.44 \\
\hline D-B & 3 & 15 & 45.866 & 0.0423 & 0.0109 & 45.95 & 45.79 \\
\hline$A-B$ & 4 & 15 & 39.73 & 0.035 & 0.009 & 39.75 & 39.65 \\
\hline C-D & 4 & 15 & 45.65 & 0.028 & 0.007 & 45.65 & 45.55 \\
\hline$A-C$ & 4 & 15 & 46.60 & 0.015 & 0.003 & 46.50 & 46.45 \\
\hline D-B & 4 & 15 & 45.87 & 0.018 & 0.004 & 45.81 & 45.75 \\
\hline$A-B$ & 7 & 15 & 39.68 & 0.038 & 0.0101 & 39.74 & 39.62 \\
\hline C-D & 7 & 15 & 45.58 & 0.033 & 0.007 & 45.67 & 45.55 \\
\hline$A-C$ & 7 & 15 & 46.49 & 0.050 & 0.013 & 46.57 & 46.42 \\
\hline D-B & 7 & 15 & 45.78 & 0.043 & 0.011 & 45.83 & 45.71 \\
\hline$A-B$ & 8 & 15 & 39.68 & 0.041 & 0.0075 & 39.77 & 39.62 \\
\hline C-D & 8 & 15 & 45.60 & 0.039 & 0.0072 & 45.68 & 45.53 \\
\hline$A-C$ & 8 & 15 & 46.48 & 0.032 & 0.0059 & 46.54 & 46.42 \\
\hline D-B & 8 & 15 & 45.75 & 0.039 & 0.0072 & 45.82 & 45.70 \\
\hline
\end{tabular}

hypochlorite and $2 \%$ glutaraldehyde solution were used for $10 \mathrm{~min}$, all bacteria were eliminated, thus preventing infection transmission to dental staff and laboratory without affecting the quality and dimensions of the impressions. ${ }^{[20]}$

The other part of the hypothesis must be rejected because the use of immersion disinfection with $1 \%$ sodium hypochlorite and $2 \%$ glutaraldehyde for $60 \mathrm{~min}$ can alter the dimensions of the alginate impressions which affect later on the casts poured from them.
However, the statistical analysis of the study founded that there was a statistically significant difference between measurements were taken from the metallic master model and the immediately poured casts of alginate impressions after immersion in $1 \%$ sodium hypochlorite and 2\% glutaraldehyde for $60 \mathrm{~min}$.

For interpretation, these may be attributed to the pressure applied during making the impression because alginate impressions are elastic material can save these changes, so after a period of time, 
Ismail, et al.: Impression disinfectant solutions

\begin{tabular}{|c|c|c|c|c|c|}
\hline Measurement & The difference between the mean ( 3 ) & SE & Degree of freedom & Value $t$ calculated & Value $P<0.05$ \\
\hline$\overline{A-B}$ & 0.140 & 0.0137 & 14 & 2.46 & 0.027 \\
\hline C-D & 0.078 & 0.0205 & 14 & 3.82 & 0.023 \\
\hline$A-C$ & 0.122 & 0.0351 & 14 & 3.49 & 0.004 \\
\hline D-B & 0.097 & 0.0109 & 14 & 4.90 & 0.041 \\
\hline Measurement & The difference between the mean (4) & SE & Degree of freedom & Value $t$ calculated & Value $P<0.05$ \\
\hline$\overline{A-B}$ & 0.142 & 0.0137 & 14 & 2.47 & 0.002 \\
\hline C-D & 0.099 & 0.0205 & 14 & 3.81 & 0.024 \\
\hline$A-C$ & 0.125 & 0.0351 & 14 & 3.50 & 0.004 \\
\hline D-B & 0.101 & 0.0109 & 14 & 3.92 & 0.002 \\
\hline Measurement & The difference between the mean (7) & SE & Degree of freedom & Value $t$ calculated & Value $P<0.05$ \\
\hline A-B & 0.004 & 0.010 & 14 & 0.456 & 0.655 \\
\hline C-D & 0.008 & 0.008 & 14 & 0.933 & 0.367 \\
\hline$A-C$ & 0.023 & 0.013 & 14 & 1794 & 0.094 \\
\hline D-B & 0.013 & 0.010 & 14 & 1.22 & 0.239 \\
\hline Measurement & The difference between the mean (8) & SE & Degree of freedom & Value $t$ calculated & Value $P<0.05$ \\
\hline$\overline{A-B}$ & 0.005 & 0.007 & 14 & 0.705 & 0.486 \\
\hline$C-D$ & 0.001 & 0.007 & 14 & 1886 & 0.069 \\
\hline$A-C$ & 0.001 & 0.005 & 14 & 1865 & 0.072 \\
\hline D-B & 0.002 & 0.007 & 14 & 1432 & 0.163 \\
\hline
\end{tabular}

internal efforts and hydraulic mechanical power were liberated as healing occurred and ions released. Another contributing factor may be the dimensions of alginate impression increase due to the nature of the chemical composition of its components due to impregnation and absorption of water by dissolved salts remaining involved in alginate components as potassium alginate before they turn to insoluble alginate are calcium alginate. ${ }^{[21,22]}$

Furthermore, there were no statistically significant differences in stone casts which immediately poured from ZOE paste impressions' dimensions after immersion in $1 \%$ sodium hypochlorite and $2 \%$ glutaraldehyde for $60 \mathrm{~min}$. These may be due to the nature of the chemical composition and physical properties of ZOE paste as it is a nonelastic material which cannot recover and not affected by evaporation and absorption of water. ${ }^{[2]}$

The American Dental Council on Dental Materials in 1996 suggested the use of glutaraldehyde and sodium hypochlorite for disinfection with recommended $10 \mathrm{~min}$ immersion in sodium hypochlorite with available chlorine of $5000 \mathrm{ppm}$. The use of glutaraldehyde or iodophor is indicated for ZOE paste disinfection. For irreversible hydrocolloid impressions, immersion in hypochlorite, iodophor, or glutaraldehyde with phenolic buffer is recommended. ${ }^{[23]}$
The effectiveness of sodium hypochlorite and glutaraldehyde as a disinfectant is influenced by a number of factors including concentration and age of the solution, disinfection contact time and accessibility of the organisms, presence of organic material, presence of metal catalysts, $\mathrm{pH}$, temperature, and chemical additives to the sodium hypochlorite. ${ }^{[1]}$

The use of sodium hypochlorite for disinfection of irreversible hydrocolloid impressions appears to reduce the effects of syneresis and consequently results in casts with better surface quality than impressions rinsed only with running water. ${ }^{[3]}$ The impression materials used in the study are irreversible hydrocolloid as it is one of the impression materials used frequently in the making of a fixed as well as a removable prosthesis and $\mathrm{ZOE}$ paste as the most frequent final impression material in the complete denture.

The most common method for disinfection is spraying the disinfecting agents on alginate impressions, but some studies have shown that these impressions can be disinfected by immersion method as well. ${ }^{[17,19]}$ A number of methods for disinfection have been investigated and recommended including antimicrobial immersion system and/or spraying and then sealing in a bag or spraying system. It has been suggested that immersion system is better than spraying as the latter leads to the pooling effect and 
its effect is localized. Irreversible hydrocolloids tend to imbibe saliva and blood, so immersion system is preferable as it assures coverage of all the surfaces of the impression. ${ }^{[7]}$ Hence, the immersion method was used in the study according to this recommendation.

Blair and Wassell have suggested that all impressions regardless of the type of material should be immersed in $1 \%$ sodium hypochlorite for $10 \mathrm{~min}$. This time is considered to be the minimum required for the effective use of all disinfectants. ${ }^{[24]}$ While Amin et al. found that the best material for disinfection alginate and ZOE paste impression is the sodium hypochlorite concentration $0.5 \%$ for $10 \mathrm{~min}$ without a change in dimensions. ${ }^{[25]}$ Sheila et al. studied effect ZOE paste impression disinfection with sodium hypochlorite $1 \%$ for different time periods of 10 and $30 \mathrm{~min}$, they concluded that the dimensions did not change in all times. ${ }^{[26]}$

In the research carried out by Taylor et al. and Oderinu et al. on dimensional accuracy of disinfected alginate impressions by sodium hypochlorite, the dimensional variation in impressions was not significant, which is not consistent with our study because of the difference in methods regarding the time of preservation of impressions and sodium hypochlorite dilution. ${ }^{[27,28]}$ These results were disagreement with this study as the stone casts resulted from pouring decontaminated alginate impressions using the employed disinfectants showed slight dimensional shrinkage. This may be attributed to the processes of syneresis and imbibition to which alginate was subjected. Alginate impressions were kept in a humid atmosphere for $1 \mathrm{~h}$ before pouring the stone casts, during which the material might have been subjected to syneresis which caused shrinkage of the impression, but upon pouring the impressions with stone, the alginate imbibed the moisture of the stone mix which caused swelling of the impression and partly compensated for the syneresis shrinkage. However, all the disinfectants employed for decontaminating alginate impressions will affect the least changes in the dimensions of the resultant cast, while casts produced by pouring disinfected ZOE impressions demonstrated a slight reduction in dimensions caused by marginal swelling of ZOE impression upon exposure to the disinfectants except to $1 \%$ sodium hypochlorite which will affect a minimal and clinically insignificant expansion of the resultant casts.

The study has an implicated limitation as this in vitro study has not complied with the same effect as in vivo because it did not completely simulate the oral condition such as the presence of saliva, harbor environment of bacteria, and resiliency of oral tissue. Therefore, in the future, additional clinical studies are necessary to clarify the long-term effect of disinfectants on the dimensional accuracy of impression materials.

\section{CONCLUSIONS}

Under the limitations of the study can concluded that possibility of ZOE paste impressions disinfection with $1 \%$ sodium hypochlorite and $2 \%$ glutaraldehyde for 10 or 60 min without affecting on dimensional stability. Otherwise, for alginate impressions, only 10 min immersion in disinfectant not affecting the dimensional accuracy then must be immediately poured.

\section{Financial support and sponsorship Nil.}

\section{Conflicts of interest}

There are no conflicts of interest.

\section{REFERENCES}

1. Shambhu HS, Gujjari AK. A study on the effect on surface detail reproduction of alginate impressions disinfected with sodium hypochlorite and ultraviolet light - An in vitro study. J Indian Prosthodont Soc 2010;10:41-7.

2. Sedda M, Casarotto A, Raustia A, Borracchini A. Effect of storage time on the accuracy of casts made from different irreversible hydrocolloids. J Contemp Dent Pract 2008;9:59-66.

3. Porta SR, Gomes VL, Pavanim LA, Souza CC. Analysis of three disinfectants after immersion of irreversible hydrocolloid and ZOE paste impressions. Braz J Oral Sci 2006;5:1094-100.

4. Shaba OP, Adegbulugbe IC, Oderinu OH. Dimensional stability of alginate impression material over a four hours time frame. Nig Q J Hosp Med 2007;17:1-4.

5. Hiraguchi H, Nakagawa H, Wakashima M, Miyanaga K, Sakaguchi S, Nishiyama M. Effect of storage period of alginate impressions following spray with disinfectant solutions on the dimensional accuracy and deformation of stone models. Dent Mater J 2005;24:36-42.

6. Sukhija U, Rathee M, Kukreja N, Khindria S, Singh V, Palaskar J. Efficacy of various disinfectants on dental impression materials. Internet J Dent Sci 2010;9:1.

7. Samra RK, Bhide SV. Efficacy of different disinfectant systems on alginate and addition silicone impression materials of Indian and international origin: A comparative evaluation. J Indian Prosthodont Soc 2010;10:182-9.

8. Shetty S, Kamat G, Shetty R. Wettability changes in polyether impression materials subjected to immersion disinfection. Dent Res J (Isfahan) 2013;10:539-44.

9. Fan PL. Council on dental materials, instruments and equipment. Disinfection of impressions. J Am Dent Assoc 1991;122:110-1.

10. Bal BT, Yilmaz H, Aydin C, Yilmaz C, Al FD. Antibacterial and antifungal properties of polyether impression materials. J Oral Sci 2007;49:265-70.

11. Lepe X, Johnson GH, Berg JC, Aw TC, Stroh GS. Wettability, imbibition, and mass change of disinfected low-viscosity impression materials. J Prosthet Dent 2002;88:268-76.

12. Guidelines for Disinfection and Sterilization in Healthcare Facilities; 2008. Available from: http://www.cdc.gov/hicpac/Disinfection_ Sterilization/6_0disinfection.html\#1. [Last accessed on 2012 Mar 29]. 
13. Kumar RN, Reddy SM, Karthigeyan S, Punithavathy R, Karthik KS, Manikandan R. The effect of repeated immersion of gypsum cast in sodium hypochlorite and glutaraldehyde on its physical properties: An in vitro study. J Pharm Bioallied Sci 2012;4 Suppl 2:S353-7.

14. Johnson GH, Chellis KD, Gordon GE, Lepe X. Dimensional stability and detail reproduction of irreversible hydrocolloid and elastomeric impressions disinfected by immersion. J Prosthet Dent 1998;79:446-53.

15. Jagger DC, Vowles RW, McNally L, Davis F, O'Sullivan DJ. The effect of a range of disinfectants on the dimensional accuracy and stability of some impression materials. Eur J Prosthodont Restor Dent 2007; 15:23-8.

16. Kotsiomiti E, Tzialla A, Hatjivasiliou K. Accuracy and stability of impression materials subjected to chemical disinfection - A literature review. J Oral Rehabil 2008;35:291-9.

17. Carvalhal CI, Mello JA, Sobrinho LC, Correr AB, Sinhoreti MA. Dimensional change of elastomeric materials after immersion in disinfectant solutions for different times. J Contemp Dent Pract 2011;12:252-8

18. Walker MP, Rondeau M, Petrie C, Tasca A, Williams K. Surface quality and long-term dimensional stability of current elastomeric impression materials after disinfection. J Prosthodont 2007;16:343-51.

19. Yilmaz H, Aydin C, Gul B, Yilmaz C, Semiz M. Effect of disinfection on the dimensional stability of polyether impression materials. J Prosthodont 2007;16:473-9.

20. Bustos J, Herrera R, Gonzlez U, Martnez A, Cataln A. Effect of inmersion desinfection with $0.5 \%$ sodium hypochlorite and $2 \%$ glutaraldehyde on alginate and silicone: Microbiology and SEM study.
Int J Odontostomatol 2010;4:169-77.

21. Skinner EW, Hoblit NE. A study of the accuracy of hydrocolloid-impression. J Prosthet Dent 1956;6:80-6.

22. Muzaffar D, Braden M, Parker S, Patel MP. The effect of disinfecting solutions on the dimensional stability of dental alginate impression materials. Dent Mater 2012;28:749-55.

23. Infection control recommendations for the dental office and the dental laboratory. ADA Council on Scientific Affairs and ADA Council on Dental Practice.J Am Dent Assoc 1996;127:672-80.

24. Blair FM, Wassell RW. A survey of the methods of disinfection of dental impressions used in dental hospitals in the United Kingdom. Br Dent J 1996;180:369-75.

25. Amin WM, Al-Ali MH, Al Tarawneh SK, Taha ST, Saleh MW, Ereifij N. The effects of disinfectants on dimensional accuracy and surface quality of impression materials and gypsum casts. J Clin Med Res 2009;1:81-9.

26. Sheila R, Vanderlei L, Luiz A, Carla C. Analysis of three disinfectants after immersion of irreversible hydrocolloid and ZOE paste impressions. Braz J Oral Sci 2006;5:1094-1100.

27. Taylor RL, Wright PS, Maryan C. Disinfection procedures: Their effect on the dimensional accuracy and surface quality of irreversible hydrocolloid impression materials and gypsum casts. Dent Mater 2002;18:103-10.

28. Oderinu $\mathrm{OH}$, Adegbulugbe IC, Shaba OP. Comparison of the dimensional stability of alginate impressions disinfected with $1 \%$ sodium hypochlorite using the spray or immersion method. Nig Q J Hosp Med 2007;17:69-73. 